\title{
Improvement in ammonia gas sensing behavior by polypyrrole/ multi-walled carbon nanotubes composites
}

\author{
Woo Kyung Jang, Jumi Yun, Hyung-Il Kim and Young-Seak Lee \\ Department of Fine Chemical Engineering and Applied Chemistry, BK21-E²M, Chungnam National University, Daejeon 305-764, Korea
}

\author{
Article Info \\ Received 12 January 2012 \\ Accepted 5 April 2012 \\ *Corresponding Author \\ E-mail: hikim@cnu.ac.kr \\ Tel: $+82-42-821-6694$

\section{Open Access} \\ DOI: http://dx.doi.org/ \\ 10.5714/CL.2012.13.2.088 \\ This is an Open Access article distributed \\ under the terms of the Creative Commons \\ Attribution Non-Commercial License \\ (http://creativecommons.org/licenses/ \\ by-nc/3.0/) which permits unrestricted \\ non-commercial use, distribution, and \\ reproduction in any medium, provided \\ the original work is properly cited.
}

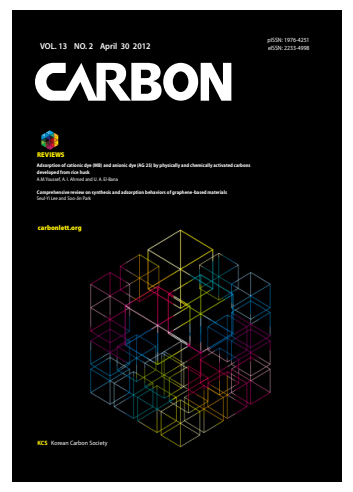

http://carbonlett.org

pISSN: 1976-4251

elSSN: 2233-4998

Copyright $\odot$ Korean Carbon Society

\begin{abstract}
Polypyrrole (PPy)/multi-walled carbon nanotubes (MWCNTs) composites were prepared by in situ polymerization of pyrrole on the surface of MWCNTs templates to improve the ammonia gas sensing properties. PPy morphologies, formed on the surface of MWCNTs, were investigated by field emission scanning electron microscopy. The thermal stabilities of the PPy/MWCNTs composites were improved as the content of MWCNTs increased due to the higher thermal stability of the MWCNTs. PPy/MWCNTs composites showed synergistic effects in improving the ammonia gas sensing properties, attributed to the combination of efficient electron transfer between PPy/MWCNTs composites and ammonia gas, and the reproducible electrical resistance variation on PPy during the gas sensing process.
\end{abstract}

Key words: ammonia, polypyrrole, multi-walled carbon nanotube, composite, gas sensor

\section{Introduction}

Ammonia $\left(\mathrm{NH}_{3}\right)$ is a kind of gas with high toxicity. The detection of $\mathrm{NH}_{3}$ is necessary and important for environmental monitoring and chemical control in industrial, agricultural, and medical fields. For example, the maximum $\mathrm{NH}_{3}$ concentration allowed at the industrial working place is $25 \mathrm{ppm}$ for $8 \mathrm{~h}$ exposure, and $35 \mathrm{ppm}$ over a $10 \mathrm{~min}$ period [1]. However, the olfactory limit of detection of $\mathrm{NH}_{3}$ is $55 \mathrm{ppm}$ [2]. Therefore, a sensitive $\mathrm{NH}_{3}$ gas sensor must be developed for the detection of lower $\mathrm{NH}_{3}$ concentration below these limits.

$\mathrm{NH}_{3}$ gas sensors based on conventional materials such as $\mathrm{SnO}_{2}$ [3], $\mathrm{TiO}_{2}$ [4], $\mathrm{In}_{2} \mathrm{O}_{3}$ [5] , $\mathrm{WO}_{3}[6]$, and $\mathrm{ZnO}$ [7] have been developed with good responsiveness and selectivity, and fast response-recovery, that can be used in detecting the lower level presence of $\mathrm{NH}_{3}$ gas. However, these $\mathrm{NH}_{3}$ gas sensors are fabricated using metal oxides which operate effectively at temperature ranges between 150 and $400^{\circ} \mathrm{C}$, resulting in both high power consumption and complexities in integration. Thus, there is a great need to develop a new class of materials for gas sensors that have good performance at room temperature.

Carbon nanotubes' (CNTs) special geometry and their outstanding feature of surface reactivity, offer great potential for application in gas sensor devices working at room temperature [8]. However, CNTs still have certain limitations for gas sensor application, such as long recovery time, limited gas detection, and vulnerability to humidity and other gases. These limitations can be resolved effectively by forming composites with conducting polymers.

Conducting polymers such as polypyrrole (PPy) and polythiophene and their composites have been widely investigated as effective materials for chemical sensors [9-11]. Among the conducting polymers, PPy has attracted considerable attention because it varies its electrical conductivity using the redox reactions and has a good stability in both air and aqueous media [12]. Fig. 1 demonstrates the oxidation process of PPy. Some electrons are removed from PPy backbones by chemical or electrochemical oxidations, leaving positive charges on them. The resulting cation radicals are called polarons, acting as the charge carriers. Counter ions, $\mathrm{X}^{-}$, are also induced close to the polymer chains to balance the positive charges. Doped conducting 

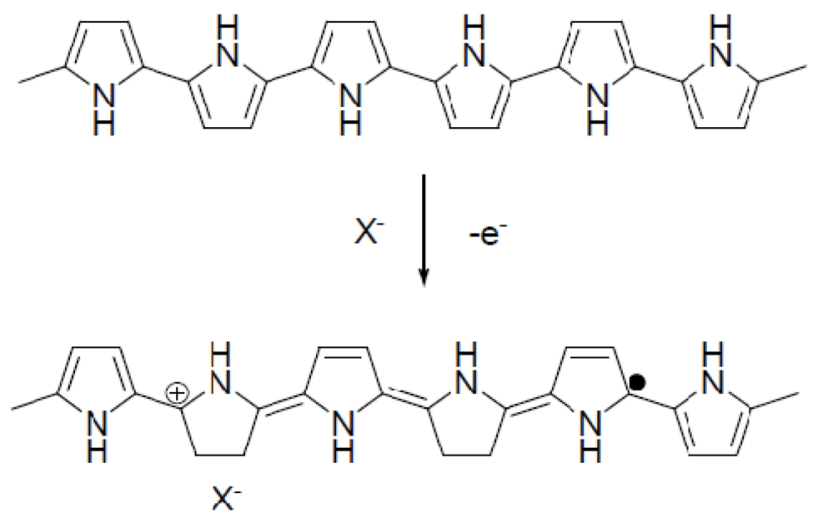

Fig. 1. Oxidation doping of polypyrrole.

polymers are semiconductors or conductors $\left(10^{0}-10^{5} \mathrm{~S} \mathrm{~cm}^{-1}\right)$. PPy and other conductive polymers have, therefore, also been classified as organic metals. There exists a wide range of applications suitable for organic metals use, such as cell culture substrates [13], field effect transistors [14], light-emitting diodes [15], solar cells [16,17], electrochromic devices [18], electronic circuits [19], elastic textile composites [20], supercapacitors for energy storage and secondary batteries [21], protection of metals [22], ion exchange membranes responding to external stimulations [23], and sensors and biosensors [24,25].

Preparation of PPy/multi-walled CNTs (MWCNTs) composites by electropolymerization on an oxidisable surface such as a $\mathrm{Cu}$ electrode have been reported, using MWCNTs as an appropriate substrate to induce the preferential deposition of PPy [26]. In our study, PPy/MWCNTs composites were prepared conveniently by in situ chemical oxidative polymerization resulting in the uniform deposition of PPy on MWCNTs without using any electrode.

Gas sensors were fabricated by spin-coating the PPy/MWCNTs composites having various compositions. The $\mathrm{NH}_{3}$ sensing properties of PPy/MWCNTs composites were investigated based on the variation of electrical resistance upon gas adsorption. This study aims to investigate the synergistic effects in improving the gas sensing properties based on the combination of electrical properties of MWCNTs and PPy.

\section{Experimental}

\subsection{Materials}

Pyrrole monomer (99\%), ammonium persulfate (APS), and MWCNTs were obtained from Sigma Aldrich. The diameter of the MWCNTs was between 110 and $170 \mathrm{~nm}$, and purity of the MWCNTs was over $90 \%$. Sodium dodecyl sulfate as surfactant was obtained from ICN Biomedicals. Hydrogen peroxide $\left(\mathrm{H}_{2} \mathrm{O}_{2}\right)$ was purchased from Kanto chemical.

\subsection{Synthesis of PPy and PPy/MWCNTs com- posites}

PPy was synthesized by free radical chemical oxidative polymerization through the direct route using $\mathrm{H}_{2} \mathrm{O}_{2}$ as oxidant.
Three gram of pyrrole monomer was dropped into distilled water and stirred continuously for $10 \mathrm{~min}$. Then $4.5 \mathrm{~mL}$ of $\mathrm{H}_{2} \mathrm{O}_{2}$ was added to the pyrrole solution. $0.8 \mathrm{~g}$ of APS dissolved in $10 \mathrm{~mL}$ distilled water was slowly added to the pyrrole solution and the reactant solution was polymerized for $4 \mathrm{~h}$ at $0^{\circ} \mathrm{C}$ with constant stirring. The synthesized PPy was filtered and rinsed several times with distilled water, methanol, and acetone, respectively. The PPy powder was dried under vacuum at $40^{\circ} \mathrm{C}$ for $24 \mathrm{~h}$.

$\mathrm{PPy} / \mathrm{MWCNTs}$ composites were synthesized using in situ chemical oxidative polymerization on the MWCNT template. The polymerization of pyrrole was carried out in distilled water using $\mathrm{H}_{2} \mathrm{O}_{2}$ as oxidant for pyrrole and APS as initiator. Various contents of MWCNTs $(0,0.5,1.0,3.0$, and $5.0 \mathrm{wt} \%)$ were dispersed in the surfactant solution and ultrasonicated over $1 \mathrm{~h}$. Three gram of pyrrole monomer was added into the MWCNTs dispersed mixture and stirred continuously for 10 min. Then $4.5 \mathrm{~mL}$ of $\mathrm{H}_{2} \mathrm{O}_{2}$ was added to the reactant solution followed by the slow addition of $0.8 \mathrm{~g}$ of APS, dissolved in $10 \mathrm{~mL}$ distilled water, to the reactant solution. The template polymerization was carried out for $4 \mathrm{~h}$ at $0^{\circ} \mathrm{C}$ with constant stirring. The synthesized PPy/MWCNTs composites were filtered and rinsed several times with distilled water, methanol, and acetone, respectively. The composite powders were dried under vacuum at $40^{\circ} \mathrm{C}$ for $24 \mathrm{~h}$. Five different composite samples, such as PPy/0 wt\%-MWCNTs, PPy/0.5 wt \%-MWCNTs, PPy/1 wt \%-MWCNTs, PPy/3 wt $\%$-MWCNTs, and $\mathrm{PPy} / 5 \mathrm{wt} \%$-MWCNTs, were named as PPy, 0.5-PPC, 1-PPC, 3-PPC, and 5-PPC, respectively.

\subsection{Preparation of the gas sensor}

The PPy/MWCNTs composites $(0.1 \mathrm{~g})$ were dispersed in acetone $(5 \mathrm{~g})$ and ultrasonicated for $30 \mathrm{~min}$ to disperse the samples uniformly in the acetone. Then the dispersion $(0.01 \mathrm{~g})$ was dropped onto a silicon wafer by using a micro-pipette (Ovation pipette, Vistalab) and spin-coated (spin coater, ACE-200) at 900 rpm for $4 \mathrm{~min}$. The coated wafer was heated to remove the solvent at $40^{\circ} \mathrm{C}$ for $10 \mathrm{~min}$. The thickness of the coating layer was $15 \pm 1 \mu \mathrm{m}$.

\subsection{Measurement of gas sensing properties}

In order to evaluate the gas sensing properties of composites, their electrical resistance was measured using a programmable electrometer (Keithley 6514). The setup of the gas sensor system is depicted in Fig. 2. The gas sensing device was prepared by using two $\mathrm{Pt}$ electrodes and $\mathrm{SiO}_{2}$ plate, as shown in previous work $[27,28]$. This measurement was performed in a stainless steel chamber with a volume of $1500 \mathrm{~cm}^{3}$. The chamber was connected to gas cylinders $\left(\mathrm{NH}_{3}\right.$ and air). The prepared sample gas sensor was placed in a sealed chamber under vacuum at a pressure of $1 \times 10^{-3}$ torr. Air was injected into the chamber to stabilize the electrical resistance of the gas sensor. The air was used as the carrier gas for the control of gas concentrations. The mixture of two different gases was then prepared with a concentration of $33.2 \mathrm{ppm} \mathrm{NH}_{3}$ in air and injected into the chamber. The gas feeding rate was kept constant at $500 \mathrm{sccm}$ in all cases. The change in electrical resistance was measured at $298 \pm 1 \mathrm{~K}$. When the electrical resistance was stable under the $\mathrm{NH}_{3}$ gas in- 


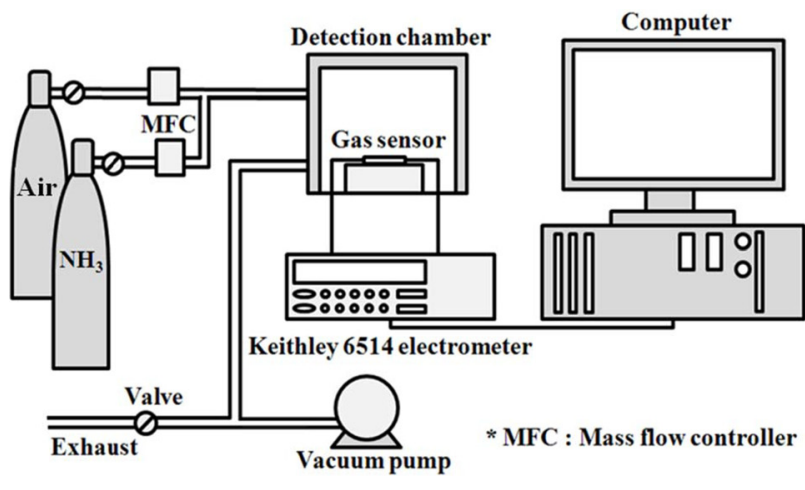

Fig. 2. Schematic diagram of the gas sensing property measurement.

jection, the injection of $\mathrm{NH}_{3}$ gas was turned off and the recovery of electrical resistance was observed. The adsorbed gases on the gas sensors were removed by heating the sensors to $373 \mathrm{~K}$ at a pressure of $1 \times 10^{-3}$ torr for $5 \mathrm{~min}[27,28]$. Recovery testing was carried out four times.

The gas sensitivity $(\mathrm{S})$ is expressed by the following equation [29,30]:

$$
S(\%)=\frac{\Delta R}{R_{0}} \times 100=\frac{R_{g}-R_{0}}{R_{0}} \times 100
$$

where $\mathrm{R}_{0}$ is the resistance due to the air and $\mathrm{R}_{\mathrm{g}}$ is the resistance measured upon exposure to $\mathrm{NH}_{3}$ gas.

\subsection{Characterization}

Field emission scanning electron microscopy (FE-SEM, Hitachi, S-5500) was used to investigate the surface morphology of the prepared gas sensors. FE-SEM measurements were conducted at $5 \mathrm{kV}$. SEM images were taken without prior treatment in order to ensure the acquisition of accurate images. Thermogravimetric analysis (TGA) was performed under nitrogen flow

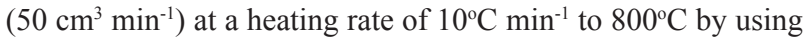
Perkin Elmer TGA5OH thermogravimetric analyzer.

\section{Results and Discussion}

\subsection{Morphology}

FE-SEM images of PPy and PPy/MWCNTs composites (0.5PPC, 1-PPC, 3-PPC, 5-PPC) are presented in Fig. 3. The granular structure of PPy is seen in Fig. 3a. PPy was coated uniformly on the MWCNTs templates while maintaining the granular structure as shown in Figs. 3b-e.

The layer structures of PPy were formed successfully on the outer surface of MWCNTs. In addition, the size reduction of PPy clusters was observed as MWCNTs content increased. These morphological characteristics were expected to play an important role in the $\mathrm{NH}_{3}$ sensing performance of the PPy/MWCNTs composites.

\subsection{Thermal stability}

The thermal stabilities of PPy and PPy/MWCNTs composites were investigated by TGA as shown in Fig. 4. The PPy/MWCNTs composites showed improved thermal stability compared with the PPy alone. MWCNTs are well known scavengers of free radicals [31]. MWCNTs, which were dispersed uniformly in the PPy matrices, retarded the thermal decomposition of the composites effectively. Although the PPy showed poor thermal stability, with an initial decomposition temperature of $250^{\circ} \mathrm{C}$ [32], the thermal properties of the PPy/MWCNTs composites were improved by incorporating the MWCNTs.
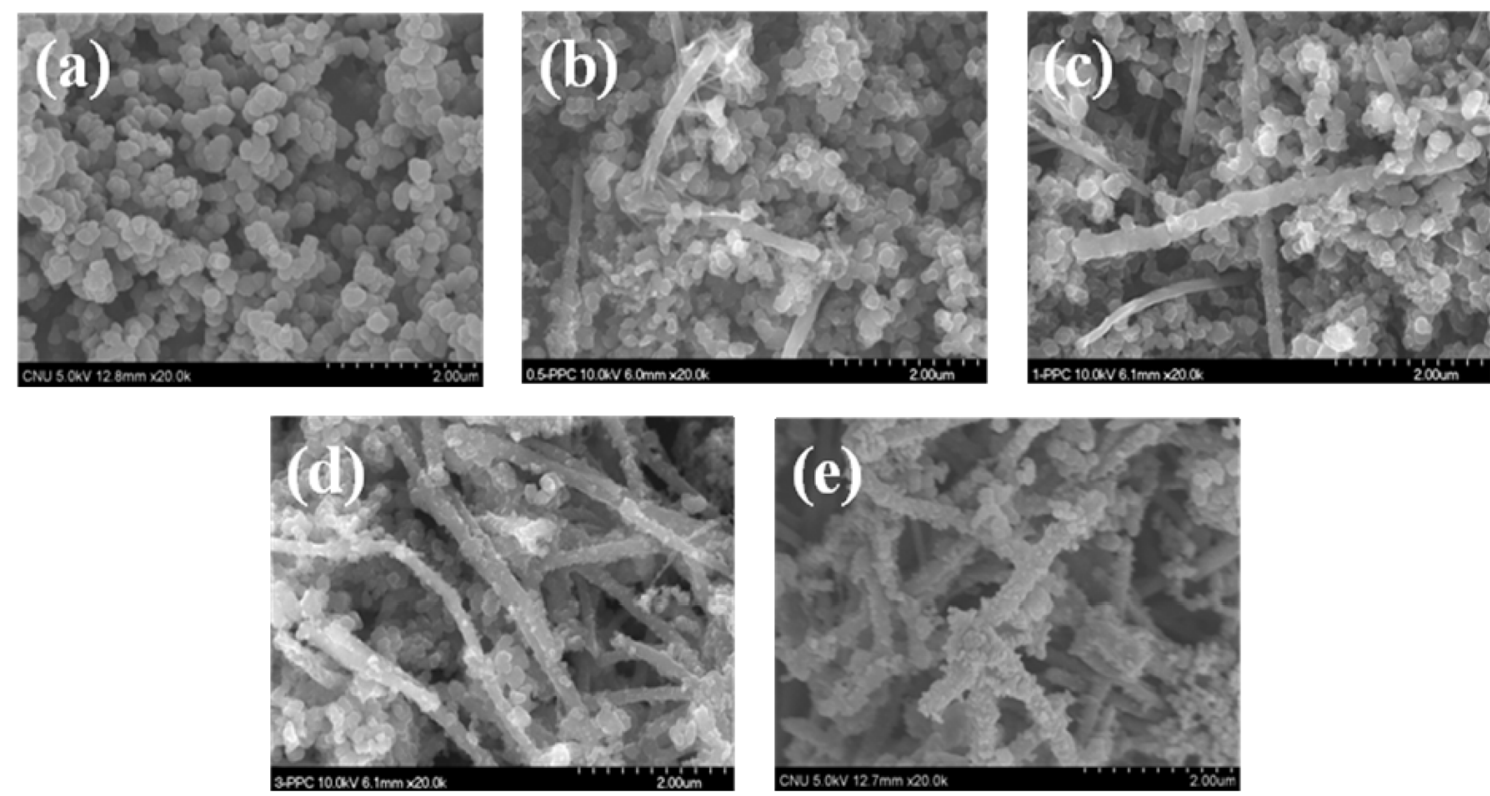

Fig. 3. Field emission scanning electron microscopy images of (a) polypyrrole, (b) 0.5-PPC, (c) 1-PPC (d) 3-PPC, and (e) 5-PPC. 


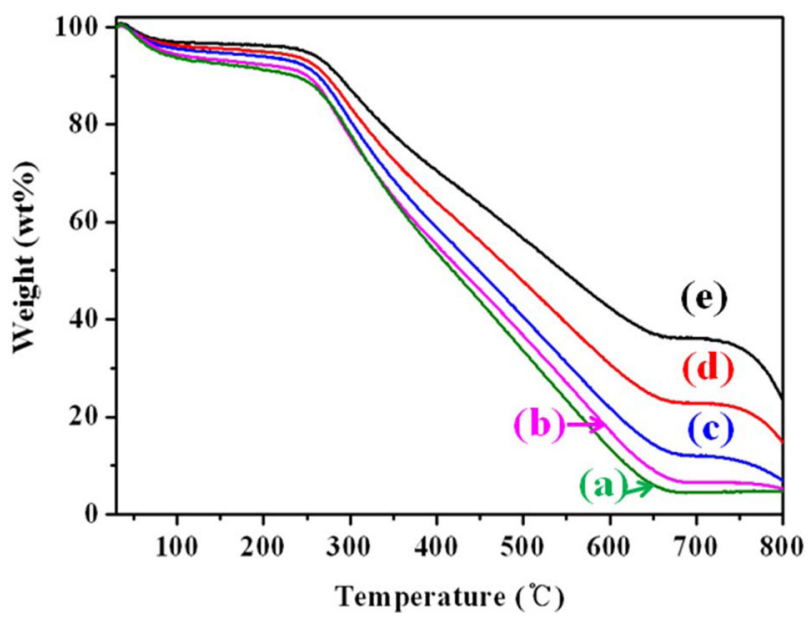

Fig. 4. Thermogravimetric analysis thermograms of (a) polypyrrole (b) 0.5-PPC, (c) 1-PPC, (d) 3-PPC, and (e) 5-PPC.

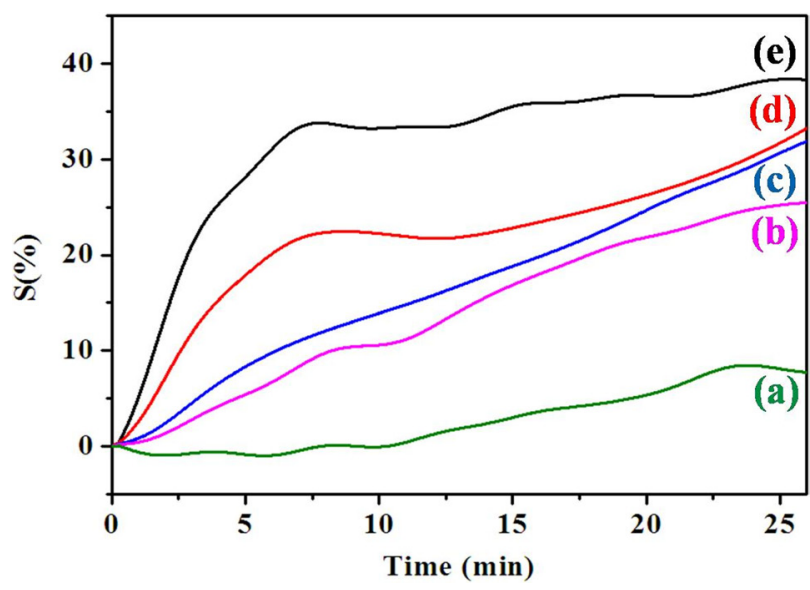

Fig. 5. Ammonia gas sensibility of (a) polypyrrole, (b) 0.5-PPC, (c) 1-PPC, (d) 3-PPC, and (e) 5-PPC.

\subsection{Gas sensitivity by resistive response}

Fig. 5 presents the $\mathrm{NH}_{3}$ gas sensitivity of various PPy/MWCNTs composites as measured by changes in the electrical resistance. The gas sensitivity of PPy and various PPy/MWCNTs composites was investigated based on two different factors, namely, the response time and the sensing intensity. PPy/ MWCNTs composites usually exhibited a change in electrical resistance in accordance with the typical characteristics of a ptype semiconductor. When this occurs with a p-type conducting polymer, the doping level as well as the electric conductance of the conducting polymer is enhanced. Generally, the electrons travel from CNTs to the $\mathrm{NH}_{3}$ gas (reducing gas), resulting in the increase of electrical resistance [33]. The following reactions are possibly involved in the $\mathrm{NH}_{3}$ gas sensing process [34,35]:

$$
\begin{array}{ll}
\mathrm{PPy}^{+}+\mathrm{NH}_{3} \rightarrow \mathrm{PPy}^{0}+\mathrm{NH}_{3}^{+} & \text {Adsorption } \\
\mathrm{PPy}^{0}+\mathrm{NH}_{3}^{+} \rightarrow \mathrm{PPy}^{+}+\mathrm{NH}_{3} & \text { Desorption }
\end{array}
$$

Based on this mechanism, all p-type conducting polymers are

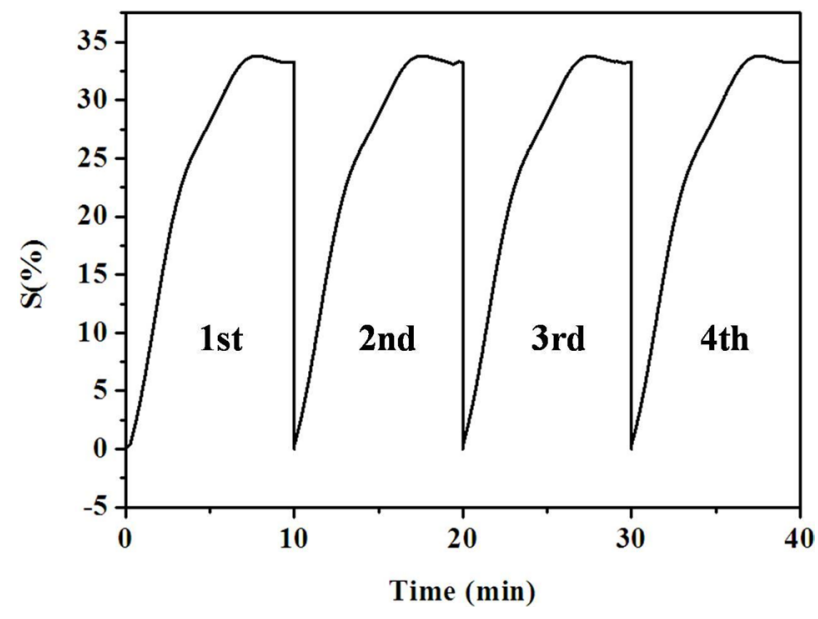

Fig. 6. Reproducibility of resistive response to the repeated exposures to ammonia gas for 5-PPC.

expected to de-dope under an $\mathrm{NH}_{3}$ gas atmosphere. It was found that a resistance increase occurred upon reaction with $\mathrm{NH}_{3}$ gas.

In this study, the gas sensitivity of various PPy/MWCNTs composites was evaluated to investigate the synergistic effects of PPy and MWCNTs. The variation in electrical resistance is attributed to the electron charge transfer between $\mathrm{NH}_{3}$ gas and the surface of PPy/MWCNTs composites. The PPy sample showed continuously increased resistivity during the initial $25 \mathrm{~min}$, with the slow response to $\mathrm{NH}_{3}$ gas showing the lack of sensitivity in gas sensing properties. This drawback was overcome by forming a composite with MWCNTs.

The sensitivity for $\mathrm{NH}_{3}$ gas was improved significantly as MWCNTs content was increased in the PPy/MWCNTs composites. The 5-PPC sample showed not only the highest sensitivity change of $65 \%$ but also the fastest response time of less than 10 min for $\mathrm{NH}_{3}$ gas among the prepared PPy/MWCNTs composite samples. 5-PPC showed about 15 times higher sensitivity for $\mathrm{NH}_{3}$ gas compared with PPy due to the synergistic effect of PPy and MWCNTs based on the combination of electrical properties of the MWCNTs and PPy. The conducting polymer-coated MWCNTs showed the unique combination of effects on both the efficiency of adsorption of gas and the resistive response, resulting in the improvement in gas sensing properties. The improved sensitivity for $\mathrm{NH}_{3}$ gas seems to be attributable to the effective electron charge transfer in the interface between $\mathrm{PPy} / \mathrm{MWCNTs}$ composites and $\mathrm{NH}_{3}$ gas, and the resulting change in electrical resistance by the uniformly dispersed MWCNTs. The reproducibility of the gas sensor performance was also investigated every $10 \mathrm{~min}$ by evacuating the gas in the chamber at a pressure of $1 \times 10^{-3}$ torr. The gas sensing behavior of the 5-PPC in the cyclic exposures to $\mathrm{NH}_{3}$ gas is shown in Fig. 6. Excellent reproducibility was observed for the 5-PPC sample, showing over $90 \%$ recovery.

\section{Conclusions}

The composites of PPy and MWCNTs were prepared by in situ chemical oxidative template polymerization on the surface of MWCNTs, as effective $\mathrm{NH}_{3}$ gas sensing materials. PPy was formed uniformly on the surface of the MWCNTs as confirmed 
by FE-SEM images. The grain size of the PPy decreased as MWCNTs content increased. The thermal stability of the PPy coating on MWCNTs was improved by the effect of oxygen radical scavenger of the MWCNTs. The improved gas sensitivity for $\mathrm{NH}_{3}$ was attributed to the effective electron charge transfer at the interface between PPy/MWCNTs composites and $\mathrm{NH}_{3}$ gas, and the efficient electron transfer by MWCNTs. PPy/MWCNTs composites showed the synergistic combination effects of efficient adsorption and conduction resulting in the improvement of gas sensing properties by dispersing MWCNTs uniformly in PPy. The reproducibility of gas sensing behavior was also investigated every $10 \mathrm{~min}$ by evacuating the gas in the chamber at a pressure of $1 \times 10^{-3}$ torr. Excellent reproducibility was observed for the PPy/MWCNTs composites showing over $90 \%$ recovery. The high-performance $\mathrm{NH}_{3}$ gas sensor could be prepared based on the composites of PPy and MWCNTs.

\section{References}

[1] Christie S, Scorsone E, Persaud K, Kvasnik F. Remote detection of gaseous ammonia using the near infrared transmission properties of polyaniline. Sensors Actuators B: Chem, 90, 163 (2003). http:// dx.doi.org/10.1016/S0925-4005(03)00036-4.

[2] Bendahan M, Lauque P, Lambert-Mauriat C, Carchano H, Seguin JL. Sputtered thin films of $\mathrm{CuBr}$ for ammonia microsensors: morphology, composition and ageing. Sensors Actuators B: Chem, 84, 6 (2002). http://dx.doi.org/10.1016/S0925-4005(02)00004-7.

[3] Wang YD, Wu XH, Su Q, Li YF, Zhou ZL. Ammonia-sensing characteristics of $\mathrm{Pt}$ and $\mathrm{SiO}_{2}$ doped $\mathrm{SnO}_{2}$ materials. Solid State Electron, 45, 347 (2001). http://dx.doi.org/10.1016/S0038-1101(00)00231-8.

[4] Hayakawa I, Iwamoto Y, Kikuta K, Hirano S. Gas sensing properties of platinum dispersed-TiO2 thin film derived from precursor. Sensors Actuators B: Chem, 62, 55 (2000). http://dx.doi. org/10.1016/s0925-4005(99)00303-2.

[5] Mbarek H, Saadoun M, Bessaïs B. Screen-printed Tin-doped indium oxide (ITO) films for $\mathrm{NH}_{3}$ gas sensing. Mater Sci Eng C, 26, 500 (2006). http://dx.doi.org/10.1016/j.msec.2005.10.037

[6] Wang X, Miura N, Yamazoe N. Study of $\mathrm{WO}_{3}$-based sensing materials for $\mathrm{NH}_{3}$ and $\mathrm{NO}$ detection. Sensors Actuators B: Chem, 66, 74 (2000). http://dx.doi.org/10.1016/S0925-4005(99)00410-4.

[7] Patil DR, Patil LA, Patil PP. $\mathrm{Cr}_{2} \mathrm{O}_{3}$-activated $\mathrm{ZnO}$ thick film resistors for ammonia gas sensing operable at room temperature. Sensors Actuators B: Chem, 126, 368 (2007). http://dx.doi. org/10.1016/j.snb.2007.03.028.

[8] Tran TH, Kwon JH, Lee KS, Lee JW, Ju BK. pH sensor using carbon nanotubes as sensing material. First International Conference on Communications and Electronics, Hanoi, Vietnam, 490 (2006). http://dx.doi.org/10.1109/CCE.2006.350876.

[9] Lange U, Roznyatovskaya NV, Mirsky VM. Conducting polymers in chemical sensors and arrays. Anal Chim Acta, 614, 1 (2008). http://dx.doi.org/10.1016/j.aca.2008.02.068.

[10] de Souza JEG, dos Santos FL, Barros-Neto B, dos Santos CG, de Melo CP. Polypyrrole thin films gas sensors. Synth Met, 119, 383 (2001). http://dx.doi.org/10.1016/s0379-6779(00)01051-1.

[11] Ram MK, Yavuz O, Lahsangah V, Aldissi M. CO gas sensing from ultrathin nano-composite conducting polymer film. Sensors Actuators B: Chem, 106, 750 (2005). http://dx.doi.org/10.1016/j. snb.2004.09.027.
[12] Albuquerque JE, Mattoso LHC, Balogh DT, Faria RM, Masters JG, MacDiarmid AG. A simple method to estimate the oxidation state of polyanilines. Synth Met, 113, 19 (2000). http://dx.doi. org/10.1016/s0379-6779(99)00299-4.

[13] Song HK, Toste B, Ahmann K, Hoffman-Kim D, Palmore GTR. Micropatterns of positive guidance cues anchored to polypyrrole doped with polyglutamic acid: a new platform for characterizing neurite extension in complex environments. Biomaterials, 27, 473 (2006). http://dx.doi.org/10.1016/j.biomaterials.2005.06.030.

[14] Dimitrakopoulos CD, Malenfant PRL. Organic thin film transistors for large area electronics. Adv Mater, 14, 99 (2002). http://dx.doi.org/10.1002/1521-4095(20020116)14:2<99::aidadma99>3.0.co;2-9.

[15] Kraft A, Grimsdale AC, Holmes AB. Electroluminescent conjugated polymers - seeing polymers in a new light. Angew Chem Int Ed, 37, 402 (1998). http://dx.doi.org/10.1002/(sici)15213773(19980302)37:4<402::aid-anie402>3.0.co;2-9.

[16] Huynh WU, Dittmer JJ, Alivisatos AP. Hybrid nanorod-polymer solar cells. Science, 295, 2425 (2002). http://dx.doi.org/10.1126/ science. 1069156.

[17] Sun B, Marx E, Greenham NC. Photovoltaic devices using blends of branched CdSe nanoparticles and conjugated polymers. Nano Lett, 3, 961 (2003). http://dx.doi.org/10.1021/n10342895.

[18] Argun AA, Cirpan A, Reynolds JR. The first truly all-polymer electrochromic devices. Adv Mater, 15, 1338 (2003). http://dx.doi. org/10.1002/adma.200305038.

[19] Crone B, Dodabalapur A, Lin YY, Filas RW, Bao Z, LaDuca A, Sarpeshkar R, Katz HE, Li W. Large-scale complementary integrated circuits based on organic transistors. Nature, 403, 521 (2000). http://dx.doi.org/10.1038/35000530.

[20] Kim HK, Kim MS, Chun SY, Park YH, Jeon BS, Lee JY, Hong YK, Joo J, Kim SH. Characteristics of electrically conducting polymercoated textiles. Mol Cryst Liq Cryst, 405, 161 (2003). http://dx.doi. org/10.1080/15421400390263550.

[21] Hughes M, Shaffer MSP, Renouf AC, Singh C, Chen GZ, Fray DJ, Windle AH. Electrochemical capacitance of nanocomposite films formed by coating aligned arrays of carbon nanotubes with polypyrrole. Adv Mater, 14, 382 (2002). http://dx.doi.org/10.1002/15214095(20020304)14:5<382::aid-adma382>3.0.co;2-y.

[22] Rahman SU, Abul-Hamayel MA, Aleem BJA. Electrochemically synthesized polypyrrole films as primer for protective coatings on carbon steel. Surf Coat Technol, 200, 2948 (2006). http://dx.doi. org/10.1016/j.surfcoat.2005.04.012.

[23] Gardner JW, Bartlett PN. Application of conducting polymer technology in microsystems. Sensors Actuators A: Physical, 51, 57 (1995). http://dx.doi.org/10.1016/0924-4247(95)85004-x.

[24] Mazzoldi A, Della Santa A, De Rossi D. Conducting polymer actuators: properties and modeling. In: Osada Y, De Rossi DE, eds. Polymer Sensors and Actuators, Springer, Berlin, Germany, 207 (2000).

[25] Hagleitner C, Hierlemann A, Lange D, Kummer A, Kerness N, Brand O, Baltes H. Smart single-chip gas sensor microsystem. Nature, 414, 293 (2001). http://dx.doi.org/10.1038/35104535.

[26] Arami H, Mazloumi M, Khalifehzadeh R, Emami SH, Sadrnezhaad SK. Polypyrrole/multiwall carbon nanotube nanocomposites electropolymerized on copper substrate. Mater Lett, 61, 4412 (2007). http://dx.doi.org/10.1016/j.matlet.2007.02.015.

[27] Kauffman DR, Star A. Carbon nanotube gas and vapor sensors. Angew Chem Int Ed, 47, 6550 (2008). http://dx.doi.org/10.1002/ 
anie.200704488.

[28] Im JS, Kim JG, Lee YS. Fluorination effects of carbon black additives for electrical properties and EMI shielding efficiency by improved dispersion and adhesion. Carbon, 47, 2640 (2009). http:// dx.doi.org/10.1016/j.carbon.2009.05.017.

[29] Makeiff DA, Huber T. Microwave absorption by polyanilinecarbon nanotube composites. Synth Met, 156, 497 (2006). http:// dx.doi.org/10.1016/j.synthmet.2005.05.019.

[30] Singh V, Mohan S, Singh G, Pandey PC, Prakash R. Synthesis and characterization of polyaniline-carboxylated PVC composites: application in development of ammonia sensor. Sensors Actuators B: Chem, 132, 99 (2008). http://dx.doi.org/10.1016/j. snb.2008.01.007.

[31] Kodjie SL, Li L, Li B, Cai W, Li CY, Keating M. Morphology and crystallization behavior of HDPE/CNT nanocomposite. J Macromol Sci B, 45, 231 (2006). http://dx.doi.org/
10.1080/00222340500522299.

[32] Mohammad F, Calvert P, Billingham N. Thermal stability of electrochemically prepared polythiophene and polypyrrole. Bull Mater Sci, 18, 255 (1995). http://dx.doi.org/10.1007/bf02749663.

[33] Wang SG, Zhang Q, Yang DJ, Sellin PJ, Zhong GF. Multi-walled carbon nanotube-based gas sensors for $\mathrm{NH}_{3}$ detection. Diamond Relat Mater, 13, 1327 (2004). http://dx.doi.org/10.1016/j.diamond. 2003.11.070.

[34] Bhat NV, Gadre AP, Bambole VA. Structural, mechanical, and electrical properties of electropolymerized polypyrrole composite films. J Appl Polym Sci, 80, 2511 (2001). http://dx.doi. org/10.1002/app.1359.

[35] Yoon H, Chang M, Jang J. Sensing behaviors of polypyrrole nanotubes prepared in reverse microemulsions: effects of transducer size and transduction mechanism. J Phys Chem B, 110, 14074 (2006). http://dx.doi.org/10.1021/jp061423b. 